\title{
Cation Size Dependent DNA Adsorption Kinetics and Packing Density on Gold Nanoparticles: An Opposite Trend
}

\author{
Biwu Liu, Erin Y. Kelly and Juewen Liu* \\ Department of Chemistry, Waterloo Institute for Nanotechnology, University of Waterloo, Waterloo, Ontario, Can- \\ ada $\mathrm{N}_{2} \mathrm{~L}_{3} \mathrm{G} 1$.
}

Supporting Information Placeholder

\begin{abstract}
The property of DNA is strongly influenced by counter ions. Packing a dense layer of DNA onto a gold nanoparticle (AuNP) surface generates a diverse range of novel physical properties such as a sharp melting transition, protection of the DNA against nuclease and enhanced penetration of biological membranes. In this work, we show that the density of the DNA on AuNPs is a function of counter ion size, where smaller $\mathrm{Li}^{+}$allows $\sim 30 \%$ more DNA packing compared to the larger $\mathrm{Cs}^{+}$. At the same time, the initial DNA adsorption kinetics are slower with $\mathrm{Li}^{+}$compared to that with $\mathrm{Cs}^{+}$, which is attributed to the easier dehydration of $\mathrm{Cs}^{+}$. This is also supported by $\mathrm{Cs}^{+}$being much more effective in aggregating citrate-capped AuNPs than $\mathrm{Li}^{+}$. This work suggests that detailed physicochemical information at the bio/nano interface can be obtained by using counter ions as probes.
\end{abstract}

\section{Introduction}

Since DNA is a polyelectrolyte, counter ions play a critical role in affecting its structure and property. Modulation of DNA properties such as melting temperature $\left(T_{\mathrm{m}}\right)$, conformation, and chemical functions (e.g. metal binding and DNAzyme activity) are commonly cited examples. ${ }^{1}$ A further level of complexity is introduced when DNA is densely immobilized on a surface to form a polyelectrolyte corona. DNA-functionalized gold nanoparticles (AuNPs) are such an example, which have become a cornerstone in nanotechnology and have found a broad range of applications including biosensor development, ${ }^{2-4}$ drug delivery,5, 6 and directed assembly of materials. ${ }^{7,} 8$

A key feature of this conjugate is the extremely high DNA density. This dense layer of highly negatively charged DNA has generated a number of important physicochemical and biochemical consequences. First, due to both steric and charge stabilization, this conjugate has high colloidal stability. In addition, this conjugate binds to its complementary DNA (cDNA) orders of magnitude tighter compared to the affinity achieved by the free DNA. Finally, the highly charged surface allows its penetration through various biological membranes. 9
A high DNA density is partly enabled by the high radii of curvature of small AuNPs. For example, DNA on a $10 \mathrm{~nm}$ AuNP is $\sim 4$ times more dense compared to that on a planar gold surface. ${ }^{10}$ In addition, counter ions or salts play a critical role. In fact, immobilizing thiolated DNA onto AuNPs relies on a process called 'salt aging', where $\mathrm{NaCl}$ is gradually added to the mixture of DNA and AuNPs over 1-2 days. The final DNA density is a function of salt concentration and a higher salt allows for a higher DNA density. ${ }^{11}$ Other factors, such as $\mathrm{pH}$ and surfactant can influence the kinetics and capacity of DNA loading as well. ${ }^{12,13}$ At the same time, the dense DNA layer attracts counter ions to produce a high local salt concentration, which is directly responsible for the sharp melting transition and elevated melting temperature for DNAlinked AuNPs. ${ }^{14}$ The immobilized DNA is protected against nuclease degradation, which is attributed to the inactivation of the enzyme by the high local $\mathrm{Na}^{+}$concentration. ${ }^{15}$

So far, $\mathrm{NaCl}$ has been the most commonly used salt. We reason that at the crowded AuNP/DNA interface, the size of counter ions might play a critical role in determining DNA packing, thus influencing the conjugate property. Therefore, in addition to their charge, cation size needs to be considered as well. Herein, we study DNA adsorption kinetics, AuNP aggregation and DNA loading density in Group $1 \mathrm{~A}$ cations ranging from $\mathrm{Li}^{+}$to $\mathrm{Cs}^{+}$. Interestingly, cations that promote faster DNA adsorption result in a lower DNA packing density on AuNPs. Our work suggests that these cations can be used as probes at bio/nano interfaces.

\section{Materials and Methods}

Chemicals. All the DNA samples were from Integrated DNA Technologies (IDT, Coralville, IA). The sequence of DNA1 is SH-A ${ }_{9}$ CCCAGGTTCTCT-FAM (FAM = carboxyfluorescein). Citrate-capped $13 \mathrm{~nm}$ diameter AuNPs were prepared following literature reported methods. ${ }^{16}$ PEG 20,00o was from VWR and all the monovalent salts are from Sigma-Aldrich. The DNAs used for $T_{\mathrm{m}}$ measurement are TCACAGATGCGTAlexaFluor488 and Iowa Black FQ-ACGCATCTGTGA, which form a duplex. The thiolated compounds and all the salts were purchased from Sigma-Aldrich.

AuNP aggregation. A final of $5 \mathrm{nM}$ AuNPs were used and the chloride salts of the monovalent cations were added. After 1 $\mathrm{h}$, the color of the AuNPs was recorded using a digital cam- 
era. To prepare SAM capped AuNPs, $10 \mathrm{nM}$ AuNPs were mixed with o.1 mM of thiolated compounds.

DNA Adsorption Kinetics. To study the effect of monovalent ions on the adsorption kinetics, $10 \mathrm{nM}$ DNA1 was dissolved in $90 \mu \mathrm{L}$ of HEPES buffer $(5 \mathrm{mM}, \mathrm{pH} 7.6)$ containing various salts ( $\mathrm{LiCl}, \mathrm{NaCl}, \mathrm{KCl}, \mathrm{RbCl}, \mathrm{CsCl}, 150 \mathrm{mM}$ ) and $2 \%$ PEG 20 , ooo. The fluorescence intensity at $520 \mathrm{~nm}$ was monitored for 2 min using a plate reader (Tecan Infinite F2ooPro). AuNPs were incubated with $2 \%$ of PEG 20 , ooo overnight. After a quick addition of $10 \mu \mathrm{L}$ of AuNPs-PEG solution (DNA:AuNP = 20:1), the fluorescence was scanned for another $20 \mathrm{~min}$. In another experiment, $1 \mathrm{nM}$ DNA1 was dissolved in $90 \mu \mathrm{L}$ of the same HEPES buffer containing varying salts (one with $32 \mathrm{mM}$ $\mathrm{LiCl}$, and the other with $30 \mathrm{mM} \mathrm{LiCl}$ and $2 \mathrm{mM} \mathrm{CsCl}$ ). Then citrate-capped AuNPs (no PEG treatment) were added to induce adsorption.

DNA adsorption capacity. To study adsorption capacity, DNA1 was loaded onto AuNPs using the salt-aging method. ${ }^{16}$ AuNPs were first incubated with $3 \mu \mathrm{M}$ DNA overnight (DNA:AuNP $=300: 1$ ), then the $\mathrm{pH}$ was adjusted by HEPES (final concentration $=5 \mathrm{mM}$ ). The salt concentrations were gradually increased to $100 \mathrm{mM}$ or $300 \mathrm{mM}$ with various salts ( $\mathrm{LiCl}, \mathrm{NaCl}, \mathrm{KCl}, \mathrm{RbCl}$, or $\mathrm{CsCl}$ ) in $10 \mathrm{~h}$. After overnight incubation, the AuNPs were centrifuged ( $15 \mathrm{~min}$, 15, ooo rpm or 21,130 $\mathrm{g}$ ), and the supernatant was removed. Then AuNPs were washed with HEPES $5 \mathrm{mM}$ for four times and disperse in HEPES buffer. The amount of adsorbed DNA was determined by fluorescence measurement after treating AuNPsDNA conjugates with $10 \mu \mathrm{M} \mathrm{KCN}$. All the experiments were run in triplicate and the error bars represent the standard deviation.

$T_{m}$ measurement. The fluorophore labelled DNA $(5 \mu \mathrm{M})$ and quencher labelled DNA $(6 \mu \mathrm{M})$ were first hybridized. The final test solution contained 5 mM HEPES ( $\mathrm{pH} 7.6)$ and various concentrations of the monovalent salts. The final fluorophore-labelled DNA concentration was $250 \mathrm{nM}$. $15 \mu \mathrm{L}$ of the sample was transferred into a PCR plate and the plate was sealed. The melting curves were collected using a real time PCR thermocycler (CFX96, Bio-Rad) with heated lid. The temperature increase was at each degree. The fluorescence in the FAM channel was read after a holding time of 20 sec.

\section{Results and Discussion}

To achieve reproducible DNA attachment, it is important to ensure the colloidal stability of AuNPs during experiments. Citrate-capped AuNPs are only stabilized by the electrostatic repulsion from weakly adsorbed citrate. Since AuNPs experience a much larger attractive van der Waals (vdW) force compared to most other nanoparticles (e.g. 90 times larger than polystyrene particles of the same size), ${ }^{17}$ AuNPs are easily aggregated by adding just a low concentration of salt to screen charge repulsion. Therefore, we need to establish the concentration limit of each salt. The aggregation of AuNPs can be conveniently monitored using UV-vis spectroscopy or by visual inspection, where dispersed AuNPs are red and aggregated ones are purple or blue. According to the DLVO theory, these monovalent salts should have the same charge screening power. Interestingly, we observed that larger cations are much more effective in inducing AuNP aggregation, where color change to blue was observed with just $10 \mathrm{mM} \mathrm{CsCl}$ (Figure $1 \mathrm{~A}$ ). On the other hand, the
AuNPs were more stable in smaller cations and they remained stably dispersed even in $50 \mathrm{mM} \mathrm{LiCl}$. Similar observations were also made with divalent metal ions (Figure ${ }_{1 B} \mathrm{~B}$ ), where $0.3 \mathrm{mM} \mathrm{Ba}^{2+}$ induced aggregation but the particles remained stable in the same concentration of $\mathrm{Mg}^{2+}$.

At first glance, an easy explanation is the Hofmeister series. $\mathrm{Cs}^{+}$is higher on the list than $\mathrm{Li}^{+}$, meaning $\mathrm{Cs}^{+}$is more effective in precipitating negatively charged proteins. However, we do not believe this is directly applicable to AuNPs since the highest salt concentration we used was just $\sim 100$ $\mathrm{mM}, \mathrm{Cs}^{+}$induced aggregation at $\sim 10 \mathrm{mM}$ (Figure $1 \mathrm{~A}$ ), and $\mathrm{Ba}^{2+}$ induced aggregation below $0.3 \mathrm{mM}$ (Figure $1 \mathrm{~B}$ ). In such a low ionic strength, the main effect of salt should be ionic (e.g. charge screening) instead of hydrophobic for describing the Hofmeister series. ${ }^{18,}{ }^{19}\{$ Merk, 2014 \#12163\}\{Pfeiffer, 2014 \#12162\}

Our data indicate that large cations are better at screening charge repulsion. With the same charge, larger cations have a lower charge density and are less hydrated or more easily dehydrated compared to the smaller ones (see Table 1). This might allow the larger cations to bind directly to an AuNP surface through ion pair interactions (e.g. inner sphere), since they can be more easily dehydrated. ${ }^{20-22}$ To further test this hypothesis, we treated our AuNPs with thiol containing small molecules to form a self-assembled monolayer (SAM). Carboxyl groups are known to have strong affinity with divalent cations. When capped with MPA containing a single carboxyl group (Figure ${ }_{1} \mathrm{C}$ ), the AuNPs were more stable compared to that capped with MCSA, which has a dicarboxyl group (Figure $1 \mathrm{D}$ ). For example, only $0.1 \mathrm{mM} \mathrm{Ba}^{2+}$ induced full aggregation of $10 \mathrm{nM}$ AuNPs in Figure $\mathrm{iD}$, where each AuNP can be allocated only 10,00o $\mathrm{Ba}^{2+}$ ions if $\mathrm{Ba}^{2+}$ are fully localized around AuNPs. This number is approaching the number of surface gold atoms, which is a strong support of specific chemical interaction. Such direct ion binding is very efficient for charge screening (e.g. the concept of Stern layer), where larger cations bring a more significant potential drop within the Stern layer. [4-2] This notion, in particular, is supported by introducing such strong ligands. Since the divalent ions show the same trend with the monovalent in all the cases, the hypothesis of $\mathrm{Cs}^{+}$directly adsorbing onto the AuNP surface is supported. Further evidence supporting this hypothesis comes from the DNA adsorption studies described below. 

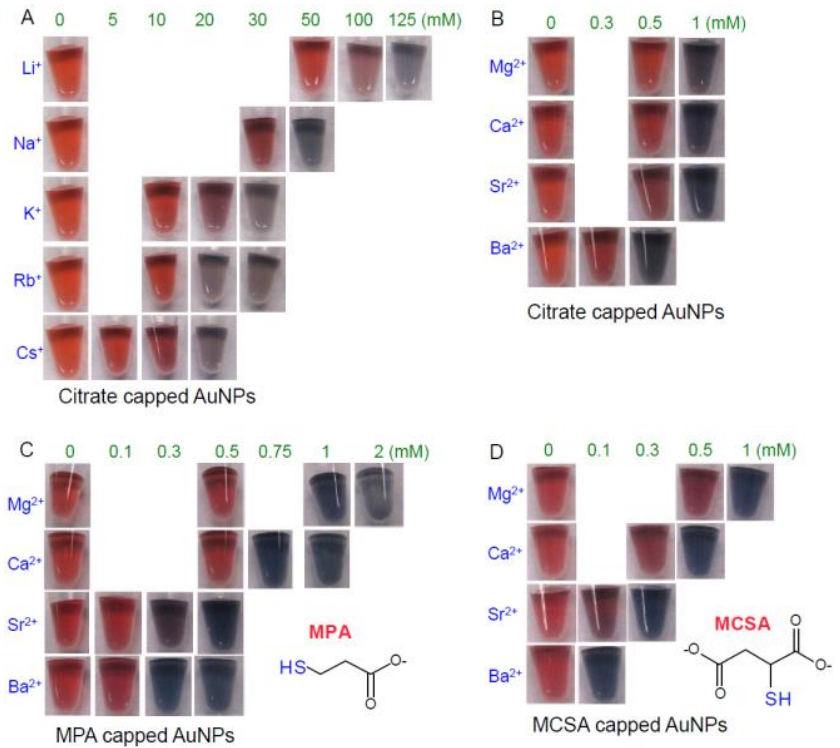

Figure 1. Photographs of citrate-capped $13 \mathrm{~nm}$ AuNPs (A) and silica nanoparticles (B) in the presence of various concentrations of monovalent chloride salts. Dispersed AuNPs are red while a purple or blue color indicates aggregation. For silica nanoparticles, aggregation was visualized after a brief centrifugation (blue arrows).

After understanding the colloidal stability of AuNPs in each type of salt, we next studied the kinetics of DNA adsorption. It has been established that thiolated DNA adsorption by gold follows a two-step process. First, at low DNA density, the attached DNA tends to lie flat on the surface since the DNA bases also have strong affinity towards the surface (although not as strong as thiol). With increasing DNA concentration enabled by adding more salt, the adsorbed bases are gradually displaced by thiol to force the DNA into an upright conformation. Counter ions play two roles in this process: 1 ) screening charge repulsion between DNA and AuNPs; and 2) screening charge repulsion among immobilized DNA. Therefore, we measure two parameters to reflect these two roles of the counter ions. The first parameter is the initial adsorption kinetics, which is measured by fluorescence quenching of a FAM-labeled DNA at low DNA concentrations. The second parameter is the final DNA loading capacity after salt aging with a high concentration of DNA over a long time, where the system is approaching equilibrium.

To measure the initial adsorption kinetics, FAM-labeled DNA and $13 \mathrm{~nm}$ AuNPs were mixed at a ratio of 20:1. To maintain AuNP stability, the salt concentration should be limited to $\sim 5 \mathrm{mM}$ based on our data in Figure $1 \mathrm{~A}$. However, this ionic strength is too low to adsorb DNA (data not shown). To solve this problem, we included $2 \%$ polyethylene glycol $(\mathrm{PEG}$, molecular weight $=20,000)$ in the system to increase AuNP stability through depletion stabilization, ${ }^{23}$ where no aggregation was observed with even $150 \mathrm{mM}$ salt. To measure the initial adsorption kinetics, we employed two types of FAM-labeled DNA. First, non-thiolated FAM- $A_{15}$ (i.e. 15-mer adenine homopolymer) was tested (Figure $2 \mathrm{~A}$ ). The adsorption kinetics of $F A M-A_{15}$ is progressively faster with larger cations. It needs to be noted that the difference between $\mathrm{Li}^{+}, \mathrm{Na}^{+}$and $\mathrm{K}^{+}$is quite small in this experiment, which might be due to limitations intrinsic to this experi- ment (e.g. the use of PEG and the small signal change). What can be concluded is that the adsorption rate is significantly faster with $\mathrm{Cs}^{+}$compared to that with $\mathrm{Li}^{+}$.[1-1] As a control, DNA was tested in the absence of added salt (Figure 2A, black trace), where the signal remained stable. To eliminate artifacts that might be caused by PEG, we carried out another experiment in the presence of $32 \mathrm{mM} \mathrm{Li}^{+}$or $30 \mathrm{mM} \mathrm{Li}{ }^{+}$ plus $2 \mathrm{mM} \mathrm{Cs}^{+}$, so that the total ionic strength is the same (Figure $2 \mathrm{~B}$ ). Note that the citrate-capped AuNPs are stable in $30 \mathrm{mM} \mathrm{Li}^{+}$. We still observed much faster DNA attachment for the $\mathrm{Cs}^{+}$containing sample. Such a large kinetic difference from just $2 \mathrm{mM} \mathrm{Cs}^{+}$in a background of $30 \mathrm{mM} \mathrm{Li}^{+}$strongly suggests a strong interaction between $\mathrm{Cs}^{+}$and AuNP surface.

To test generality of this observation, we next repeated the same experiments with a thiolated DNA. The overall adsorption kinetics are much faster in this case due to the presence of the thiol label. (Figure $2 \mathrm{C}, \mathrm{D}$ ). $\mathrm{Li}^{+}, \mathrm{Na}^{+}$and $\mathrm{K}^{+}$still resulted in a similarly slow rate of DNA adsorption, while $\mathrm{Rb}^{+}$and $\mathrm{Cs}^{+}$ were progressively faster. These experiments indicate that $\mathrm{Cs}^{+}$is not only more effective in inducing AuNP aggregation, but also for the attachment of DNA to AuNPs. The origin of these properties should be the same (i.e. $\mathrm{Cs}^{+}$is more effective in screening charge repulsion). A scheme showing this comparison is in Figure $3 \mathrm{~A}$. Based on the kinetic results, one might expect that the final DNA loading capacity is also higher with $\mathrm{Cs}^{+}$. However, as shown below, the opposite was observed.
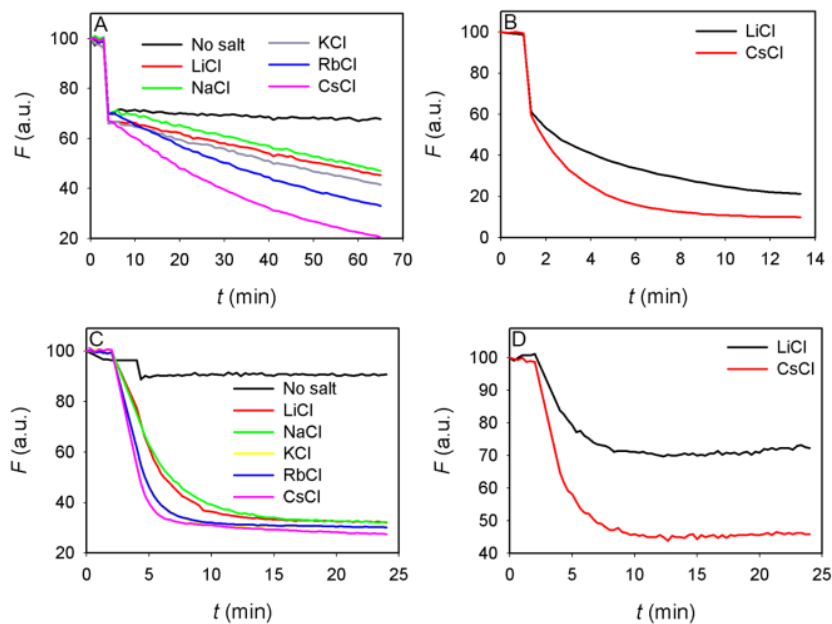

Figure 2. Kinetics of FAM- $A_{15}(\mathrm{~A})$ and DNA1 (FAM and thiolated dual labeled) (C) adsorption as a function of cation size in $2 \%$ PEG 20,0oo. The salt concentrations were $150 \mathrm{mM}$. Kinetics of FAM-A $\mathrm{A}_{15}$ (B) and DNA1 (D) adsorption in $2 \mathrm{mM}$ $\mathrm{Li}^{+}$or $\mathrm{Cs}^{+}$with $30 \mathrm{mM}$ background $\mathrm{Li}^{+}$. Decrease of fluorescence intensity indicates DNA adsorption.

Table 1. Size of the cations. Data taken from Ref. ${ }^{24}$

\begin{tabular}{l|l|l|l|l|l}
\hline Ion & $\mathrm{Li}^{+}$ & $\mathrm{Na}^{+}$ & $\mathrm{K}^{+}$ & $\mathrm{Rb}^{+}$ & $\mathrm{Cs}^{+}$ \\
$R(\mathrm{~nm})^{\mathrm{a}}$ & 0.07 & 0.102 & 0.138 & 0.149 & 0.170 \\
$R_{\mathrm{h}}(\mathrm{nm})^{\mathrm{b}}$ & 0.34 & 0.276 & 0.232 & 0.228 & 0.226 \\
\hline
\end{tabular}

a. $\mathrm{R}=$ ionic radius. ${ }^{\mathrm{b}}$. $\mathrm{R}_{\mathrm{h}}=$ hydrated ion radius.

Next, we carried out the standard salt aging protocol for 3 days to immobilize a high density of DNA on the AuNPs. The DNA density results are plotted in Figure $4 \mathrm{~A}$, where the final salt concentration was $100 \mathrm{mM}$ or $300 \mathrm{mM}$. For each3 cation, the final DNA density was higher with a higher salt 
concentration, consistent with previous reports using $\mathrm{NaCl} .{ }^{11}$ At each ionic strength, the density of DNA was the highest with $\mathrm{Li}^{+}$and it progressively dropped with increasing cation size. The density was $\sim 30 \%$ higher with $\mathrm{Li}^{+}$compared to that with $\mathrm{Cs}^{+}$. It is interesting to note that this loading capacity trend is completely reversed from the initial adsorption kinetics.
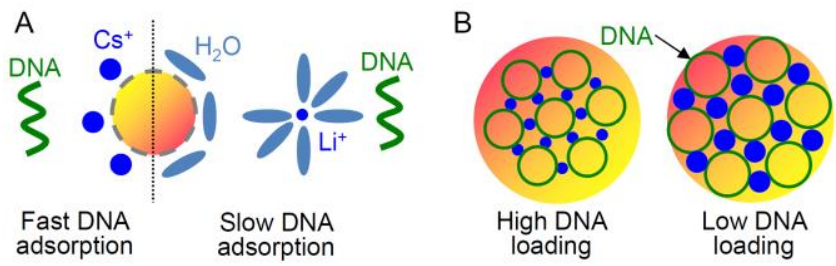

Figure 3. (A) A scheme explaining how AuNPs initially adsorb DNA faster in the presence of large cations since they can be more easily dehydrated and are more effective in screening long-ranged electrostatic repulsion. (B) The final density of DNA is higher with small cations due to their thermodynamically stronger interaction with DNA and smaller geometric size that allows for higher DNA packing density.

At first glance, this is consistent with $\mathrm{Li}^{+}$being the smallest ion and thus allows for the packing of more DNA. It is important to note that since $\mathrm{Li}^{+}$has the highest charge density, it actually has the largest hydrated size (Table 1). Therefore, the counter ions are likely to at least partially dehydrate at the interface to account for our DNA density results. To test this hypothesis, we assume a simple model that under the closely packed state, $n$ DNA molecules surround on each AuNP (cross section area of DNA $=A_{\mathrm{D}}$ ) and each DNA has $m$ salt ions (not shared; cross section area $=A_{\mathrm{S}}$ ). The total cross section area should add up to the surface area of the AuNP of $615 \mathrm{~nm}^{2}$ (assuming radius $=7 \mathrm{~nm}$ by considering the spacer due to the alkyl-thiol chain between DNA and gold surface; and all the space on the gold is occupied by either DNA or cation); that is $615=n\left(A_{\mathrm{D}}+m A_{\mathrm{s}}\right)$. We plotted $615 / n$ as a function of $A_{S}$ in Figure ${ }_{4} \mathrm{C}$, and obtained $A_{D}=3.6 \mathrm{~nm}^{2}$ and $m=$ 13.5 by linear fitting. A double-stranded DNA has a cross section area of $\sim 3.2 \mathrm{~nm}^{2}$ and this is similar to the number from our model using ss-DNA. Since our calculation is based on a $2 \mathrm{D}$ cross-section shell, each DNA can contribute only one negative charge. Therefore, it is unlikely that 13.5 cations can be packed around that negative charge. In other words, it is unlikely that the size difference between $\mathrm{Li}^{+}$and $\mathrm{Cs}^{+}$can account for the $30 \%$ difference in DNA loading capacity.
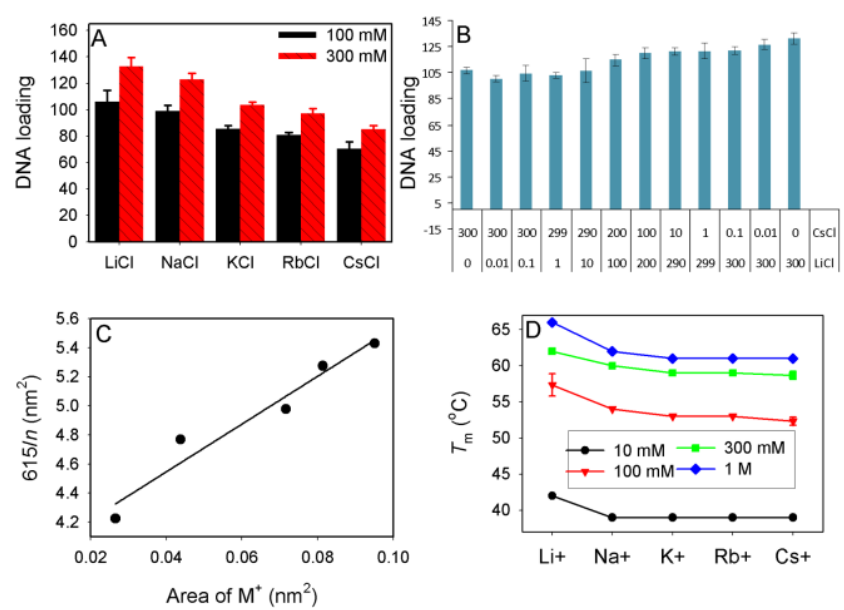

Figure 4. (A) DNA loading density (number of DNA on each AuNP) after salt aging with a final salt concentration of 100 or $300 \mathrm{mM}$. (B) DNA loading density with a mixture of $\mathrm{Li}^{+}$ and $\mathrm{Cs}^{+}$, but keeping the total ionic strength $300 \mathrm{mM}$. (C) Estimation of DNA size and the number of counter ions for each DNA based on the data in (A) using a simple geometric model. (D) $T_{\mathrm{m}}$ as a function of cation concentration and size.

In addition to size, specific chemical interactions with DNA must also play an important role. Another possibility is that the effective size of DNA is smaller in $\mathrm{Li}^{+}$if we ignore the size of the counter ions. That means $\mathrm{Li}^{+}$is better at screening the charge repulsion between DNA strands and allows DNA to be packed more closely. The binding affinity between monovalent cations and DNA has been studied by a number of techniques including electrophoresis, ${ }^{25} \mathrm{NMR},{ }^{26,} 27$ atomic force microscopy, ${ }^{28}$ and electrochemistry, ${ }^{29}$ but the results are not consistent. Herein, we measured the $T_{\mathrm{m}}$ of a 12-mer DNA (Figure $4 \mathrm{D}$ ). $\mathrm{Li}^{+}$has the highest $T_{\mathrm{m}}$ in all tested concentrations. Therefore, $\mathrm{Li}^{+}$is a better DNA binder and may allow DNA to pack more closely. $3^{\circ}$ This is consistent with the higher final DNA density, which should also be a thermodynamic measurement. Since the salt aging experiment took a total of 3 days for incubation, the density of DNA in the presence of $\mathrm{Li}^{+}$must have caught up gradually. For the kinetic measurement, charge screening on AuNPs appears to be important. For the final loading, the ion size and charge density are more important (Figure ${ }_{3} \mathrm{~B}$ ). It needs to be noted that with $100 \mathrm{mM}$ and $300 \mathrm{mM} \mathrm{NaCl}$, the loading of DNA decreases almost linearly from $\mathrm{Li}^{+}$to $\mathrm{Cs}^{+}$, but the $T_{\mathrm{m}}$ difference is quite small from $\mathrm{Na}^{+}$to $\mathrm{Cs}^{+}$(i.e. $\mathrm{Li}^{+}$is significantly higher than the rest). Therefore, the ability to screen charge repulsion is unlikely to be the sole factor to determine the final DNA loading capacity. Other factors such as cation size and hydration might also contribute. [1-2]

Since the AuNP concentration is $\sim 10 \mathrm{nM}, 100 \mu \mathrm{M}$ counter ions are sufficient to compensate all the DNA charges at the interface. An interesting question is the DNA loading in a mixture of $\mathrm{Li}^{+}$and $\mathrm{Cs}^{+}$while keeping the same total ionic strength. As shown in Figure $4 \mathrm{~B}, \sim 100 \mathrm{mM} \mathrm{Li}{ }^{+}$is needed to achieve a high density of DNA. Therefore, the thermodynamic driving force for high DNA loading is not sufficiently high to compensate for the entropic loss of enriching the ions at the interface at very low $\mathrm{Li}^{+}$concentrations. Note that the capacity measurement has $\sim 20 \%$ inconsistency for experiments carried out in different days. Such measurements are quite complex, containing multiple steps and involving4 
calibration curves. The inconsistency might be related to pipetting errors, washing inconsistency, photobleaching, and timing. Therefore, it is more informative to compare the trend of loading capacity change in each experiment rather than the absolute values. [3-7]

In summary, we have made a number of interesting observations in this work. 1) Negatively charged colloids could aggregate more easily in the presence of larger cations. This happens at very low salt concentrations for AuNPs and we attributed this to larger cations being more easily dehydrated as shown in Figure $3 \mathrm{~A}$. The same trend is also observed for the initial attachment of DNA to AuNPs. 2) Despite the initial DNA attachment kinetics being slower, smaller cations allow a higher final DNA density on AuNPs. This could be a useful method to further fine tune the DNA density on AuNPs (e.g. started with the same initial DNA concentration). 3) From the pure colloidal science perspective, studying AuNPs allows us to do research in a low salt concentration region that is not accessible with other types of particles. For the comparison between AuNPs and silica, the latter takes close to $1 \mathrm{M}$ salt to aggregate, where the behavior of salt is quite different (showing more hydrophobic effects) compared to the low mM salts with AuNPs (more ionic effects).

\section{AUTHOR INFORMATION}

\section{Corresponding Author}

Email: liujw@uwaterloo.ca

\section{ACKNOWLEDGMENT}

Funding for this work is from the University of Waterloo, the Canadian Foundation for Innovation, the NSERC of Canada and the Early Researcher Award from the Ontario Ministry of Research and Innovation.

\section{REFERENCES}

1. Zhang, X.-B.; Kong, R.-M.; Lu, Y., Metal Ion Sensors Based on DNAzymes and Related DNA Molecules. Annu. Rev. Anal. Chem. 2011, 4, 105-128.

2. Rosi, N. L.; Mirkin, C. A., Nanostructures in Biodiagnostics. Chem. Rev. 2005, 105, 1547-1562.

3. Zhao, W.; Brook, M. A.; Li, Y., Design of Gold Nanoparticle-Based Colorimetric Biosensing Assays. ChemBioChem 2008, 9, 2363-2371.

4. Liu, J.; Cao, Z.; Lu, Y., Functional Nucleic Acid Sensors. Chem. Rev. 2009, 109, 1948-1998.

5. Giljohann, D. A.; Seferos, D. S.; Daniel, W. L.; Massich, M. D.; Patel, P. C.; Mirkin, C. A., Gold Nanoparticles for Biology and Medicine. Angew. Chem. Int. Ed. 2010, 49, 3280-3294.

6. Wang, H.; Yang, R. H.; Yang, L.; Tan, W. H., Nucleic Acid Conjugated Nanomaterials for Enhanced Molecular Recognition. ACS Nano 2009, 3, 2451-246o.

7. Park, S. Y.; Lytton-Jean, A. K. R.; Lee, B.; Weigand, S.; Schatz, G. C.; Mirkin, C. A., DNA-Programmable Nanoparticle Crystallization. Nature 2oo8, 451, 553-556.

8. Nykypanchuk, D.; Maye, M. M.; van der Lelie, D.; Gang, O., DNA-Guided Crystallization of Colloidal Nanoparticles. Nature 2008, 451, 549-552.

9. Cutler, J. I.; Auyeung, E.; Mirkin, C. A., Spherical Nucleic Acids. J. Am. Chem. Soc. 2012, 134, 1376-1391.
10. Hill, H. D.; Millstone, J. E.; Banholzer, M. J.; Mirkin, C. A., The Role Radius of Curvature Plays in Thiolated Oligonucleotide Loading on Gold Nanoparticles. ACS Nano 2009, 3, 418-424.

11. Jin, R.; Wu, G.; Li, Z.; Mirkin, C. A.; Schatz, G. C., What Controls the Melting Properties of DNA-Linked Gold Nanoparticle Assemblies? J. Am. Chem. Soc. 2003, 125, 16431654 .

12. Seferos, D. S.; Prigodich, A. E.; Giljohann, D. A.; Patel, P. C.; Mirkin, C. A., Polyvalent DNA Nanoparticle Conjugates Stabilize Nucleic Acids. Nano Lett. 2009, 9, 308-311.

13. Storhoff, J. J.; Elghanian, R.; Mucic, R. C.; Mirkin, C. A.; Letsinger, R. L., One-Pot Colorimetric Differentiation of Polynucleotides with Single Base Imperfections Using Gold Nanoparticle Probes. J. Am. Chem. Soc. 1998, 120, 1959-1964. 14. Bishop, K. J. M.; Wilmer, C. E.; Soh, S.; Grzybowski, B. A., Nanoscale Forces and Their Uses in Self-Assembly. Small 2009, 5, 1600-1630.

15. Pegram, L. M.; Wendorff, T.; Erdmann, R.; Shkel, I.; Bellissimo, D.; Felitsky, D. J.; Record, M. T., Why Hofmeister Effects of Many Salts Favor Protein Folding but Not DNA Helix Formation. Proc. Natl. Acad. Sci. U.S.A. 2010.

16. Bostrom, M.; Williams, D. R. M.; Ninham, B. W., Specific Ion Effects: Why DLVO Theory Fails for Biology and Colloid Systems. Phys. Rev. Lett. 2001, 87, 168103.

17. Kunz, W., Specific Ion Effects in Colloidal and Biological Systems. Curr. Opin. Colloid Interface Sci. 2010, 15, 34-39.

18. Collins, K. D., Ions from the Hofmeister Series and Osmolytes: Effects on Proteins in Solution and in the Crystallization Process. Methods 2004, 34, 300-311.

19. Calero, C.; Faraudo, J.; Bastos-Gonzalez, D., Interaction of Monovalent Ions with Hydrophobic and Hydrophilic Colloids: Charge Inversion and Ionic Specificity. J. Am. Chem. Soc. 2011, 133, 15025-15035.

2o. Salis, A.; Parsons, D. F.; Boström, M.; Medda, L.; Barse, B.; Ninham, B. W.; Monduzzi, M., Ion Specific Surface Charge Density of SBA-15 Mesoporous Silica. Langmuir 2009, 26, 2484-2490.

21. Azam, M. S.; Weeraman, C. N.; Gibbs-Davis, J. M., Specific Cation Effects on the Bimodal Acid-Base Behavior of the Silica/Water Interface. J. Phys. Chem. Lett. 2012, 3, 1269-1274. 22. Zhang, X.; Servos, M. R.; Liu, J., Ultrahigh Nanoparticle Stability against Salt, $\mathrm{Ph}$ and Solvent with Retained Surface Accessibility Via Depletion Stabilization. J. Am. Chem. Soc. 2012, 134, 9910-9913.

23. Marcus, Y., Ion Properties. Marcel Dekker: New York, 1997.

24. Hurst, S. J.; Lytton-Jean, A. K. R.; Mirkin, C. A., Maximizing DNA Loading on a Range of Gold Nanoparticle Sizes. Anal. Chem. 2oo6, 78, 8313-8318.

25. Savelyev, A.; Papoian, G. A., Electrostatic, Steric, and Hydration Interactions Favor $\mathrm{Na}^{+}$Condensation around DNA Compared with $\mathrm{K}^{+}$. J. Am. Chem. Soc. 2006, 128, 14506-14518. 26. Heddi, B.; Foloppe, N.; Hantz, E.; Hartmann, B., The DNA Structure Responds Differently to Physiological Concentrations of $\mathrm{K}^{+}$or $\mathrm{Na}^{+}$. J. Mol. Biol. 2007, 368, 1403-1411. 27. Cesare Marincola, F.; Denisov, V. P.; Halle, B., Competitive $\mathrm{Na}^{+}$and $\mathrm{Rb}^{+}$Binding in the Minor Groove of DNA. J. Am. Chem. Soc. 2004, 126, 6739-6750.

28. Vlassakis, J.; Williams, J.; Hatch, K.; Danilowicz, C.; Coljee, V. W.; Prentiss, M., Probing the Mechanical Stability of DNA in the Presence of Monovalent Cations. J. Am. Chem. Soc. 2008, 130, 5004-5005. 
29. Wang, K.; Zangmeister, R. A.; Levicky, R., Equilibrium Electrostatics of Responsive Polyelectrolyte Monolayers. J. Am. Chem. Soc. 2008, 131, 318-326. 3o. Owczarzy, R.; Moreira, B. G.; You, Y.; Behlke, M. A.; Walder, J. A., Predicting Stability of DNA Duplexes in Solutions Containing Magnesium and Monovalent Cations. Biochemistry 2008, 47, 5336-5353. 